\title{
El marqués de Altamira y el nuevo impulso colonizador en el norte novohispano 1742-1753/
}

\section{The Marquis of Altamira and the New Colonizing Drive in the North of New Spain 1742-1753}

\author{
Patricia Osante \\ Instituto de Investigaciones Históricas \\ Universidad Nacional Autónoma de México \\ In memoriam \\ María Justina Saravia Viejo
}

Este artículo se centra en la política de poblamiento que puso en marcha el auditor de Guerra y Hacienda de la real Audiencia de México, Juan Rodríguez de Albuerne, en las provincias de la frontera norte de la Nueva España. Se trata de un primer ensayo de la política reformista realizada por este funcionario virreinal, veinte años antes de la llegada del visitador José de Gálvez a la Nueva España.

Palabras Clave: Juan Rodríguez de Albuerne; Política reformista; Política de poblamiento; Nueva España.

This article is focused on the populating policy started by the auditor of War and Finance of the real Audiencia of Mexico, Juan Rodriguez de Albuerne, in the provinces of the northern borderline of New Spain. It is a first trial on the reforming policy undertaken by this viceregal officer, twenty years prior to the arrival of Inspector José de Gálvez in New Spain.

KeYwords: Juan Rodriguez de Albuerne; Reforming policy; Populating policy; New Spain. 
Mucho se ha escrito acerca de la participación pública en la Nueva España del visitador José de Gálvez y de su posterior desempeño como ministro de Indias en España. Acéptase de buen grado que la actividad reformista llevada a cabo por tan reconocido funcionario malagueño, tanto en el ámbito novohispano como en el peninsular, es referencia obligada para todo aquel que, de una u otra forma y en mayor o menor medida, aborde un tema, ya sea de carácter general o regional, que anteceda o coincida con el inicio de la aplicación de la reforma militar y administrativa emprendida por las autoridades reales en la Nueva España a mediados de la década de los sesenta del siglo XVIII.

No obstante, para profundizar un poco más en la problemática situación que se vivía en la frontera norte novohispana y poder identificar ciertos móviles políticos y económicos que llevaron al superior gobierno a promover y apoyar el proyecto reformista ejecutado por Gálvez en la frontera norte, es necesario referirse a Juan Rodríguez de Albuerne. La actividad realizada en la corte virreinal por este personaje, mejor conocido en la historiografía contemporánea como el marqués de Altamira, resulta relevante debido a que, en aras de un aprovechamiento útil del territorio, intentó llevar a cabo una reorganización integral de la estructura política, social y económica en las principales provincias septentrionales, veinte años antes de que oficialmente el visitador Gálvez pusiera en marcha la política reformista en dicha región.

De aquí entonces que uno de los propósitos de este artículo sea el de mostrar cómo Altamira, durante su gestión de auditor de Guerra y Hacienda, puso en marcha en la frontera norte ciertas medidas principalmente relacionadas con el reforzamiento del poblamiento civil, así como otras más tendientes a controlar el establecimiento y la administración de las misiones y los presidios septentrionales. No cabe la menor duda de que el auditor y sus más cercanos colaboradores aportaron sus propias ideas con el afán de consolidar el dominio español y lograr una mejor explotación de los recursos naturales y humanos en esa zona, en provecho del real gobierno. Sin embargo, en la documentación consultada sobre este asunto existe suficiente evidencia para afirmar que el funcionario en cuestión, con el propósito de favorecer al grupo de nobles propietarios al cual él pertenecía, hizo suyas también algunas de las propuestas de cambio planteadas desde mucho tiempo atrás.

Es de sobra conocido que desde mediados del siglo XVII la capitanía general del virreinato novohispano empezó a recibir numerosas solicitudes 
y proyectos pacificadores y colonizadores elaborados por diversas autoridades civiles, militares y eclesiásticas de las provincias norteñas; la mayor parte de ellos estaba encaminada a lograr la paz con los naturales y a mejorar el funcionamiento de las principales instituciones que operaban en dicho territorio para alcanzar un desarrollo social y económico de los asentamientos españoles de la zona. A pesar de las iniciativas emprendidas por las autoridades virreinales, se sabe que muchas de las propuestas no fueron escuchadas o no pudieron ser atendidas por el gobierno central, no obstante su permanente y genuina preocupación de pacificar y repoblar principalmente con españoles y demás «gente de razón» la frontera norte de la Nueva España. ${ }^{1}$

La difícil situación de la frontera norte y su necesaria transformación empezaron a cobrar más significado para los funcionarios reales en las dos primeras décadas del siglo XVIII. ${ }^{2}$ Al despuntar los años cuarenta del mencionado siglo, ya circulaba ampliamente entre las autoridades y vecinos de ciertas provincias septentrionales el deseo de llevar a cabo un cambio sustancial de las principales prácticas que aún se mantenían en dicha región en materia de defensa, colonización y reducción de los indígenas. ${ }^{3}$ Sería, sin embargo, el marqués de Altamira quien promoviera y estimulara en la corte virreinal un primer ensayo transformador en una porción del entonces llamado Seno Mexicano con la fundación, en 1748, de la Colonia del Nuevo Santander, según se verá en este artículo.

$\mathrm{Si}$ se atiende a lo anterior no se puede dejar de reparar en un asunto que, a todas luces, contribuye a terminar con la idea difundida en la historiografía contemporánea de que las reformas borbónicas que se aplicaron en la Nueva España en el siglo XVIII fueron todas pensadas y decididas desde la Península Ibérica. Hoy en día semejante afirmación, al menos para

1 Prueba de ello se puede constatar en los textos publicados por Polzer \& Sheridan, 1997. Véase Cramaussel, 1997, 39-54; Cramaussel, 2006, 16, 19, 190; Deeds, 2003, 67; Porras Muñoz, 1980, 65; Mendizábal, 1946, 180-181.

2 Por ejemplo, Francisco de Barbadillo y Vitoria estuvo comisionado en el Nuevo Reino de León de 1714 a 1716 por el gobierno virreinal para que suprimiera las congregas y combatiera los excesos perpetrados por la sociedad y el gobierno neoleonés en contra de la población indígena. Posteriormente fue designado gobernador de dicha entidad de 1719 a 1723. Archivo General de la Nación (AGNM), Reales Cédulas (duplicados), México, 38, 142-143v, 192v-201v, 222-231, 236-242; 71, 56v-58, 80v-83v. Asimismo, existe un interesante informe elaborado por Antonio Ladrón de Guevara acerca de la situación que imperaba en el Nuevo Reino de León, fechado en 1739. Polzer \& Sheridan, 1997, 77-120. Posteriormente, se llevó a cabo la conocida visita del brigadier Pedro de Rivera a los presidios norteños, entre 1724-1728, de la cual se hablará más adelante. Rivera, 1946.

3 Ortega Noriega, 2010, 85-86; Ortega Noriega y Río, 2010, 185-241; Velázquez, 1981, 80-81. 
la frontera norte, no puede sostenerse frente a la evidencia de que algunas de las propuestas de cambio de esa época surgieron de los grupos de poder novohispanos y no de la metrópoli, como se asegura. En el conjunto de las reformas contempladas y aplicadas por José de Gálvez en las provincias norteñas de la Nueva España, se llega apreciar en algunas de ellas el afán transformador del marqués de Altamira y de la elite gobernadora a la cual pertenecía.

\section{Altamira: un burócrata ilustrado}

Frente a todo lo anterior, resulta un tanto extraño descubrir cómo en los textos contemporáneos que aluden de algún modo a la organización político-administrativa, militar, económica y social de las provincias septentrionales, salvo el caso concreto del libro de María del Carmen Velázquez, ${ }^{4}$ con frecuencia se menciona el nombre de Altamira a partir de noticias aisladas en las cuales se tiende a proyectar una imagen difusa de un burócrata ilustrado de altos vuelos, diligente y puntilloso. Ni qué decir que dentro de este desdibujado perfil que se ofrece del marqués difícilmente tiene cabida la intensa actividad desplegada por dicho funcionario en la corte virreinal. A menudo se pierde de vista el interés del auditor de lograr la pacificación y el repoblamiento español de ciertos puntos estratégicos del septentrión novohispano, considerados parte importante del imperio en ultramar, que con frecuencia eran violentados por los grupos indígenas insumisos y asediados por la intromisión extranjera. ${ }^{5}$

Fue a partir de su ingreso a la real Audiencia de Guadalajara en 1728 cuando Juan Rodríguez de Albuerne encontró los mecanismos idóneos para vincularse con las familias más poderosas de la Nueva España, hasta obtener el título de marqués consorte al contraer nupcias con Luisa Pérez de Tagle Sánchez de Tagle, bisnieta del primer marqués de Altamira y heredera de dicho marquesado. Tal distinción le imprimió al estatus de hijodalgo del entonces oidor un lustre que contrastaba con su reservada personalidad. ${ }^{6}$

4 Velázquez, 1979.

5 Algunos otros autores llegan a estudiar de manera más profusa ciertos aspectos de la política promovida por Altamira. Véase, por ejemplo: Río, 1995, 48-58; Covarrubias, 2005, 280.

6 Rodríguez de Albuerne siempre se distinguió en España y en la Nueva España por su carácter reservado tanto en su desempeño como servidor real como en su vida privada. Archivo General de Indias (AGI), Indiferente General, 148, n. 41, 1, Relación de méritos y servicios del licenciado don Juan Rodríguez de Albuerne, 20 de julio de 1738. 
En su natal España el futuro marqués de Altamira estuvo lejos de pertenecer al grupo de jóvenes abogados de abolengo que solían llegar a los altos cargos públicos con el empuje del poderoso clan familiar que los cobijaba. Fue gracias a su versatilidad y a su gran capacidad de trabajo en tierras españolas que Rodríguez de Albuerne se ganó el nombramiento de oidor de la Audiencia de Nueva Galicia. Una vez instalado en dicha institución, ahora sí al amparo del importante sector de nobles propietarios de origen montañés radicado en la Nueva España, empezó a obtener el poder político y los recursos necesarios para alcanzar posteriormente el nombramiento de oidor de la real Audiencia de México de 1738 a 1741, así como su ulterior designación como auditor de Guerra y Hacienda en la mencionada institución en 1742, puesto que ocupó hasta su muerte en 1753 .

En la ciudad de México Altamira no tardó en adquirir fama de ser un oidor eficaz e ilustrado, leal a los intereses y a las directrices de la monarquía española. Sin embargo, es sabido que desde época muy temprana de su llegada a Guadalajara, su interés de estar al servicio del gobierno real lo tuvo que empatar - y en algunas ocasiones supeditar- a sus propios intereses personales y a los del grupo montañés que le dio cabida en su seno. En 1736, Juan Carrillo, oidor de la Audiencia de Guadalajara, presentó una denuncia ante el Consejo de Indias en contra del también oidor Rodríguez de Albuerne por entorpecer la justicia y practicar un activo tráfico de influencias a favor de un poderoso grupo de nobles propietarios de la región. ${ }^{8}$

De tal modo que cuando Altamira llegó a la capital novohispana, dada su reciente viudez, es factible suponer que siguió manteniendo fuertes vínculos con su acaudalada familia política. Aun más, pasado el tiempo, no solo conservó e hizo gala del título del marquesado que por derecho de consorte le pertenecía, sino que disfrutó de la cuantiosa fortuna que había heredado de su difunta esposa. Todo parece indicar que este patrimonio le permitió continuar como integrante activo del poderoso círculo de nobles propietarios hasta el fin de sus días. El grupo montañés estaba conformado, principalmente, por los marqueses de Altamira, los de San Miguel de

7 Juan Manuel Rodríguez de Albuerne Miranda y Bustos era originario de Lamuño, Asturias, donde nació en 1693. Osante, 2012, 89, 94-99 y 103.

8 En una extensa minuta Carrillo expone a las autoridades metropolitanas la difícil situación que se vivía en la Audiencia neogallega, en cuanto a la impartición de justicia con libertad y equidad, debido al control que Rodríguez de Albuerne ejercía sobre la mayor parte de los miembros de dicha institución para conducir los asuntos según su conveniencia y los del grupo de nobles propietarios al cual él pertenecía desde 1730. Serrera, 1977, 141-142. 
Aguayo y los de Xaral y Berrio, así como los condes de San Pedro del Alamo y San Mateo Valparaíso. Este poderoso clan cántabro poseía en Nueva Galicia, Nueva Vizcaya, Zacatecas, Guanajuato y Querétaro enormes e importantes haciendas, especializadas principalmente en la cría extensiva de ganado mayor y menor. ${ }^{9}$

Pero Altamira, además del poder político, económico y social que obtuviera en Guadalajara a lo largo de toda una década que duró su gestión de oidor en dicha institución, también pudo adquirir un conocimiento - si se quiere incipiente - de las necesidades de defensa y repoblamiento que se requerían en la frontera norte. Cabe ahora preguntarse de qué forma este alto funcionario obtuvo los elementos fundamentales que le dieran sustento para concretar - como lo hizo - un nuevo modelo colonizador que respondiera en cierto sentido a las expectativas de algunos grupos dominantes novohispanos con intereses muy añejos en la frontera norte, y que además lograra hermanarlo con la imperante necesidad del gobierno español de defender, controlar y explotar en su beneficio las tierras ubicadas en dicho territorio.

\section{Las propuestas del marqués}

En 1742, ya como auditor de Guerra y Hacienda en la capital virreinal, Altamira se fue transformando en un funcionario de altos vuelos. Pero tuvieron que transcurrir cuatro años más para que el marqués adquiriera un detallado y consistente conocimiento del territorio norteño. ${ }^{10}$ Durante ese periodo, a la par que se fue familiarizando con la problemática propia de dicha región, el auditor también alcanzó el prestigio y el renombre necesarios para participar de manera directa en la política sostenida por el gobierno central en los asuntos de frontera. Vemos que su habilidad de jurisconsulto pronto se dejó sentir en el marco de la Audiencia de México; a partir del conocimiento que tenía tanto de las leyes como de las necesidades de la administración para la cual laboraba, Altamira solía encontrar la forma

9 Entre las propiedades rurales de los marqueses de Altamira están la hacienda de Santa Ana Apapueco, que se extendía más allá de Pénjamo, en la región de León, con aproximadamente 40 sitios de ganado mayor. Otra de estas importantes propiedades fue la hacienda de Cuisillos, ubicada en la jurisdicción de Jala, colindante por el occidente con Buenavista, al extremo oriental del valle de Ameca, con 21 sitios de ganado mayor, uno de ganado menor y 13 caballerías de tierra. Osante, 2009, 346-347. 10 AGI, Guadalajara, 119. 
de justificar con razones de peso las disposiciones emanadas del real gobierno. Es interesante destacar la fuerza política y la seriedad con que eran tomados sus dictámenes y pareceres, ya que a través de ellos el pleno de la Audiencia podía sopesar si lo que en su momento se estaba proponiendo era lo dispuesto por las leyes o, en su caso, si era necesario recurrir a alguna opción — generalmente sugerida por el mismo auditor - para dar salida a los innumerables problemas a los que se enfrentaba de manera cotidiana la administración virreinal en el norte novohispano. ${ }^{11}$

Es verdad que el marqués nunca estuvo físicamente en el septentrión, como ocurriera con algunos destacados personajes civiles, militares y eclesiásticos de la talla de José de Gálvez, Teodoro de Croix, Pedro Tamarón y Romeral, el marqués de Rubí, Junípero Serra, Francisco Palou y Juan Agustín Morfi. Sin embargo, en su desempeño como auditor de Guerra y Hacienda, Altamira pudo, hasta cierto punto, subsanar dicha limitación mediante el sistemático y concienzudo estudio que realizara sobre el estado de la frontera norte, con el propósito «de enderezar y expeditar un gobierno local desarreglado, prácticamente sin supervisión, en manos de quien quisiera y pudiera aprovecharse de él». ${ }^{12}$ Sus múltiples dictámenes y pareceres que emitiera entre 1742 y 1743 están sustentados en un conjunto de ordenanzas, autos, consultas, informes y representaciones, así como en todo tipo de información relacionada con el septentrión que se encontraba resguardada en la capitanía general del virreinato.

Sin duda alguna, ya para entonces Altamira era un jurisconsulto bien preparado y fogueado en la política novohispana, que conocía al detalle las circunstancias históricas de la fundación y el desarrollo de cada una de las provincias norteñas, así como los principales problemas que aquejaban a sus pobladores. Tanto fue así que en los últimos siete años de su gestión en la Audiencia de México, el auditor logró traspasar los límites de la pura información que, de acuerdo con sus funciones, debía presentar a la capitanía general para ubicarse en el ámbito de un servidor real con acciones claramente reformistas que, desde el punto de vista de los funcionarios ilustrados, resultaban difíciles de objetar.

Muchas fueron las ideas y las propuestas que Altamira promoviera desde la corte virreinal para darle un nuevo aliento a la defensa y al repoblamiento español en la frontera norte de la Nueva España; pero es

11 Osante, 2012, 110-118.

12 Velázquez, 1979, 168. 
necesario acercarse a sus planteamientos con ojo crítico, ya que algunos de ellos, no se olvide, respondieron a las aspiraciones del selecto grupo de hombres prominentes al que el auditor pertenecía, interesado en el uso y la explotación de los recursos naturales y humanos de las tierras norteñas. Asimismo, se debe tener presente que en general las iniciativas que dicho funcionario planteara o, en su caso, apoyara en materia de pacificación, defensa y repoblamiento fueron contempladas por el marqués para hacerlas extensivas a los múltiples sitios estratégicos de todas las provincias ubicadas en la frontera norte de la Nueva España. Los documentos nos llevan a pensar que no fue tarea fácil para Altamira encontrar soluciones viables a los apremiantes problemas de los poblados septentrionales.

Por si fuera poco, las diversas y preocupantes noticias acerca de lo que sucedía en el norte terminaron por ser un elemento distorsionador de la realidad de la región, lo que dio origen a las múltiples y discordantes conclusiones entre las autoridades metropolitanas y las novohispanas, así como entre estas últimas y las locales. Todo ello tendió a complicar aún más el panorama para el funcionario a la hora de intentar aplicar algunas de las medidas que consideraba pertinentes para lograr ciertos cambios en las provincias norteñas.

La amenaza apache, por ejemplo, es un asunto representativo de la compleja situación. Estudios recientes han demostrado que la multicitada irrupción de los apaches en los asientos españoles ubicados en uno y otro lado del río Bravo, aunque la hubo, y de manera cruenta, también es verdad que en muchos momentos funcionó como un discurso justificador para tratar de contener - o en el mejor de los casos sortear- la creciente injerencia del gobierno real con el fin de ejercer y consolidar el poder en esas tierras. ${ }^{13}$ Es decir que, mediante la exaltación de la guerra apache, los funcionarios locales intentaron defender sus intereses y privilegios, preservando la relativa autonomía de que habían gozado a lo largo de casi dos siglos. Desde luego también contribuyó a engrosar las noticias en este sentido la irrupción en las villas españolas de diversas bandas de heterogénea composición étnica - mulatos, mestizos, negros, incluidos los indígenas desertores de las misiones y apóstatas- que en la confusión con frecuencia eran identificados como apaches. ${ }^{14}$

13 Ortelli, 2009, 82.

14 Ibidem, 71-73. 
Se puede echar mano de algunas noticias confiables para atenuar un poco más las dimensiones del conflicto apache en el norte. Se sabe, por ejemplo, las relaciones de compadrazgo establecidas entre ciertos jefes apaches y varios capitanes de presidios. Asimismo, en los informes de algunos capitanes de los presidios de la región norteña se señala el apoyo que estos llegaban a recibir de ciertos apaches durante las campañas militares realizadas para el combate y exterminio de otros grupos rebeldes que merodeaban el territorio. Este fue el caso de los últimos cocoyomes que quedaban en la región de Nueva Vizcaya. Aun así, habremos de aceptar el hecho importante de que en la década de los cuarenta del siglo XVIII el problema de la apachería adquirió nuevas dimensiones en las provincias más septentrionales de la Nueva España. ${ }^{15}$

En un principio Altamira centró su atención en el noreste, región conformada en ese tiempo por el Nuevo Reino de León, Coahuila y Texas. De las tres, Texas era para el auditor la que representaba un serio problema de indefensión y despoblamiento por la vecindad con los franceses asentados en la ribera norte del Misisipi, así como por el grado de beligerancia que se diera entre los apaches y los pobladores en la zona de San Antonio. ${ }^{16}$

En el estado de abandono en que se encontraba Texas mucho tuvo que ver el criterio utilizado por el brigadier Pedro de Rivera, luego de la visita que realizara a los presidios norteños en la década de los veinte del citado siglo XVIII. Dicho militar consideró que en esos tiempos de paz con Francia, la presencia de soldados en los asentamientos militares en la parte oriental de la provincia resultaba nula para la defensa, y que, por el contrario, estimulaba el contrabando con Luisiana. Por tal motivo, el brigadier resolvió que todos los presidios de la zona se replegaran al distrito de Béjar, dejando solo en los Adáes una guarnición entre 60 y 100 soldados. ${ }^{17}$ Es sabido que uno de los efectos nocivos de esta política aplicada por Pedro

15 A pesar de la aguerrida confrontación que se empezó a dar entre los colonos españoles y los apaches al mediar el siglo XVIII, existe evidencia acerca de la fallida intención de ciertos indígenas de integrarse como vecinos de las comunidades españolas. Un caso representativo es el del contingente apache que en 1730, luego de haberse establecido en una misión de la Pimería — por desconfianza que generaban estos grupos-, fue violentado y rechazado por los vecinos no indígenas radicados en esa porción del noroeste novohispano. Ortega Soto, 2010, 215-217. Asimismo, sobre el encuentro y la interacción entre los apaches y los españoles, véase Ortelli, 2009; AGI, Guadalajara, 513, Diario de la expedición de Berroterán; «Captain Berroteran's Report on the Condition of Nueva Vizcaya (1748)», en Polzer \& Sheridan, 1997, v. II, 167-226, 216-217.

16 Las expediciones punitivas organizadas por el marqués de Aguayo en tierras texanas, duraron 18 meses. Véase Alessio Robles, 1938, 479-487 y 559-568.

17 Navarro, 1964, 43, 60 y 73; Weber, 1992, 192 y 315-318. 
de Rivera fue la entrada de comerciantes galos al territorio español por Pachina, en el Misisipí, o por los cursos de los ríos Neches, Trinidad y Brazos, para relacionarse no solo con los indígenas de la localidad sino con los mismos españoles de la zona.

Además de todo lo anterior, la débil ocupación española en Texas se veía mayormente afectada por las más de doscientas leguas que comprendía el territorio conocido como Seno Mexicano, ubicado entre los ríos Pánuco y Nueces, donde residía una gran cantidad de grupos indígenas de cultura nómada y estacionaria. La necesidad de repoblar con españoles este enorme bolsón de tierra, para integrarlo al resto de la Nueva España y unirlo con Texas hasta la Bahía del Espíritu Santo, era un asunto que habría de resolverse precisamente a finales de la década de los cuarenta del siglo XVIII, bajo el arreglo y la orientación del marqués de Altamira. ${ }^{18}$

Antes que nada, para el auditor era necesario corregir las fallas y las deficiencias que mostraba el sistema operativo pacificador y colonizador. Después de casi 20 años de la visita del brigadier Rivera a los presidios del norte, las fuerzas sociales se habían modificado y las 25 guarniciones militares existentes, con un total de poco más de 800 efectivos, seguían representando un gasto «inútil» de 360.000 pesos anuales para la Real Hacienda. ${ }^{19}$ Lo mismo pensaba de los más de cien mil pesos que dicha institución aportaba al año para el sostenimiento de las misiones establecidas en distintas zonas del septentrión, toda vez que hasta ese momento — según su opinión - no se habían dejado de padecer «los frecuentes sustos y peligros de las invasiones y hostilidades de los indios», no solo apóstatas, sino incluso los congregados y cristianizados hacía ya más de 150 años. ${ }^{20}$ Asimismo, agregaba el funcionario que, de atender a todos los ocursos presentados a la capitanía general por gobernadores, capitanes de presidios y misioneros, donde solicitaban auxilios para contener las hostilidades de los indígenas en toda la frontera septentrional, en lugar de existir los 25 mencionados presidios, habría ya más de cien. De aquí que Altamira advirtiera repetidamente en sus dictámenes la imposibilidad para cualquier gobierno de sostener un sistema que, tal como estaba, casi nada podía resolver, y que

18 Osante, 2003, 92-102 y 301.

19 AGI, Guadalajara, 191, Dictamen del marqués de Altamira sobre el poblamiento de Nueva Vizcaya, México, 23 de diciembre de 1749.

20 Idem; Biblioteca Nacional de México, Archivo Franciscano (BNM, AF), 5/102, Dictamen del marqués de Altamira sobre reajuste de misiones en el Nuevo Reino de León y Coahuila, 27 de marzo de 1747. 
además, aseguraba, en la siguiente centuria los costos habrían de exceder los 45 millones de pesos, sin contar la cantidad de gastos que implicaban las repentinas sublevaciones indígenas de los indios ya reducidos. ${ }^{21}$

Entre los principales motivos que esgrime el funcionario respecto del precario funcionamiento de los presidios es el de no estar acordonados y a una distancia promedio de 60 leguas en un extenso territorio de más de 600 leguas de oriente a poniente que abarca desde el presidio de los Adáes, en Texas, confinante con la Luisiana francesa, hasta la península de California. ${ }^{22}$ Asimismo, atribuye a los capitanes de las guarniciones militares descuido, negligencia y total abandono. ${ }^{23}$ Refuerza el auditor su opinión adversa sobre los resultados prácticos de dicha institución con las noticias sobre el dudoso desempeño de los soldados destacados en Coahuila y Texas, quienes, dice, al parecer solo prestan a los misioneros «servicio de mayordomos de labranzas dentro de las misiones, en lugar de concretarse a defenderlas y a pacificar el territorio, según sus funciones». ${ }^{24}$

De acuerdo con Altamira, para lograr la seguridad en la frontera norte se debía retomar y perfeccionar la reforma militar iniciada por Pedro de Rivera para transformar el sistema defensivo a partir de un gobierno militar que contara con la fuerza suficiente para controlar a los presidiales, y contener las ofensivas indígenas y la amenaza extranjera. ${ }^{25}$ En el caso de los presidios la propuesta del auditor era dejar solo aquellos que resultaban plenamente necesarios, e incluso aceptaba la creación de algunos nuevos en puntos estratégicos para la defensa, siempre y cuando estuvieran acompañados del establecimiento de una o más poblaciones de españoles de cincuenta familias cada una de ellas, pues de lo contrario los asentamientos militares resultaban del todo inútiles. Pero más que crear costosos baluartes defensivos, el marqués se pronunció por ubicar, en los antiguos y nuevos poblados no indígenas, pequeños destacamentos de soldados con sus respectivos capitanes y la formación de diversas compañías volantes que se encargaran de recorrer y resguardar un determinado territorio, pero sobre todo que los efectivos militares de ambos grupos estuvieran en «consonancia y correspondencia» con los «presidiales convecinos» y con los

21 AGI, Guadalajara, 191, Dictamen sobre el poblamiento de Nueva Vizcaya.

22 AGI, México, 691, 175, Dictamen del marqués de Altamira sobre la inconveniencia de la fundación de varias misiones en el paraje de San Xavier, en Texas, México, 28 de enero de 1747.

23 AGI, Guadalajara, 191, 105, Dictamen del marqués de Altamira sobre presidios en Nueva Vizcaya, 25 de febrero de 1751.

24 Velázquez, 1974, 116.

25 Osante, 2012, 135. 
pobladores debidamente armados, a fin de obtener mejores resultados en la defensa del norte. ${ }^{26}$

Pero sin duda alguna, la más severa crítica del marqués de Altamira al antiguo sistema de pacificación y penetración en el septentrión novohispano tiende a recaer sobre los centros misionales. Consecuente con la política gubernamental del momento, en sus múltiples dictámenes y pareceres el auditor no pierde ocasión para poner en entredicho la efectividad de las misiones al señalar repetidamente el fracaso de los misioneros para propagar la fe cristiana entre los naturales del territorio. A los religiosos, en particular, les atribuye el lamentable atraso colonizador debido al poder y a los privilegios que tenían en dichas tierras. En buena medida, el auditor responsabiliza a los regulares de acaparar las mejores tierras y con ello acabar con el «antiguo ímpetu» de los conquistadores por poblar el septentrión. En uno de sus escritos, Altamira afirma en tono categórico que la falta de poblaciones de españoles se debe «al invencible, cerrado, absoluto dictamen de los religiosos que administran lo espiritual en dichas fronteras». ${ }^{27}$ Para el auditor, como para otros altos funcionarios de la corte virreinal, a todas luces resultan nocivas las leyes de división territorial que prohíben a los no indios avecindarse en los pueblos bajo el estatuto de misión. El hecho de que los asentamientos religiosos se mantengan alejados de todo contacto con los pobladores no indígenas no solo desvirtúa sus funciones sino que bajo el amparo de algunas de ellas, los indios supuestamente congregados y con nombre de cristianos, en realidad, dice, «son los peores enemigos, alcahueyes, receptores y directores de los apóstatas gentiles», con quienes habían mantenido y seguían sosteniendo permanente contacto y comerciando entre ellos. ${ }^{28}$

En 1746, el marqués propuso la secularización de las 22 misiones de Topia y Tepehuanes, y con los sínodos que se fueran liberando se planeó la creación de nuevos establecimientos religiosos en la zona del Moqui, al norte del río Gila. ${ }^{29}$ Por otra parte, el auditor señaló ciertas fallas u omisiones cometidas por los franciscanos en el noreste, detectados a raíz de la visita efectuada por José de Escandón a los centros misionales de dicha

26 BNM, AF, 44/1009, 13, Parecer del auditor, el marqués de Altamira, 18 de octubre de 1752; AGI, Guadalajara, 191, 104-105v, Dictamen del marqués de Altamira sobre presidios.

27 AGI, Guadalajara, 191, 105, Dictamen del marqués de Altamira sobre presidios.

28 Dictamen del marqués de Altamira sobre poblamiento, en Velázquez, 1979, 125.

29 No obstante que el acuerdo de establecer las nuevas fundaciones se hizo con los jesuitas, este no se llevó a cabo en ese momento debido, quizá, más que a la muerte de Altamira en 1753, a algún otro motivo de carácter político o económico. Ortega Noriega, 2010, 85. 
región. Por ejemplo, el coronel Escandón le informó al marqués de Altamira que varias misiones inexistentes recibían el sínodo del misionero; en otras más, los religiosos, sin dejar de percibir el sínodo, contaban con las obvenciones de los pobladores que bien les podían servir para su manutención, en lugar del sínodo anual que se les otorgaba. ${ }^{30}$

De aquí entonces que el marqués planeara un reajuste mediante la suspensión del sínodo de los establecimientos religiosos que presentaran las irregularidades citadas. Asimismo, pensó en fusionar de dos en dos las misiones que eran vecinas y tuvieran una escasa población de indios reducidos. También se planteó suspender la ayuda económica a todas aquellas misiones que habían sido fundadas hacía más de un siglo, y que para entonces recibían suficientes obvenciones de los vecinos que habitaban en sus inmediaciones y, en algunos casos, incluso percibían el tributo correspondiente de los indios que radicaban en la zona. ${ }^{31}$

Esto último llevó al funcionario a recomendar que tanto la custodia de Tampico como las misiones establecidas en Valle del Maíz y San Antonio de Tula, entre otras más, a la brevedad fueran convertidas en doctrinas, puesto que tenían indios reducidos que pagaban tributo. Todos estos centros misionales, junto con los de la Sierra Gorda, el Nuevo Reino de León y Coahuila, hacían un total de 47 establecimientos que ocasionaban un elevado costo a real erario, justamente porque hasta entonces no se habían podido convertir en curatos o doctrinas. De hecho, en 1751 Escandón había conseguido que cesaran doce sínodos de la custodia de Río Verde, cuatro sínodos más del Nuevo Reino de León y tres de Coahuila, al mismo tiempo que el coronel estaba tratando de que se suspendieran quince sínodos más, correspondientes a la custodia de Tampico. ${ }^{32}$

\section{Un primer ensayo transformador}

Para Altamira en este primer impulso de cambio del noreste quedaba un asunto pendiente de resolver: la ocupación oficial del Seno Mexicano.

30 Instituto Nacional de Antropología e Historia, Archivo Franciscano (INAH, AF), microfilm, rollo 17, caja 45, exp. 1032, apéndice, 1v-2, Resolución de la Junta General de Guerra y Hacienda sobre pacificación, reducción y población del Seno mexicano, México, 13 de mayo de 1748; AGNM, Provincias Internas, 173, exp. 1, 14.

31 Dictamen del marqués Altamira sobre reajuste de misiones, en Velázquez, 1979, 105.

32 AGNM, Provincias Internas, 173, exp. 1, 14; INAH, AF, microfilm, rollo 17, caja 45, 1032, apéndice, 1v-2, Resolución de la Junta General, México, 13 de mayo de 1748. 
El poblamiento español en esas tierras era visto como posible solución a los problemas indígenas y extranjeros en el golfo de México. Se trataba de un enorme espacio, casi despoblado de grupos misionales y civiles, ideal para imponer la voluntad colonizadora del gobierno central, cifrada en una nueva modalidad de arraigo familiar utilizando los recursos humanos no indígenas que habitaban en las poblaciones circundantes al territorio. Se dejaba atrás la secular idea de trasladar a distintos puntos de la Nueva España a familias procedentes de Galicia y de las islas Canarias. El gobierno real aún recordaba el tan costoso como malogrado proyecto del traslado de familias isleñas a Texas en 1731.

Para ello, las autoridades virreinales, bajo el influjo de Altamira, diseñaron una original empresa que bien podría engarzar la inquietud del gobierno central de aplicar una nueva política colonizadora con las expectativas creadas sobre las tierras del Seno Mexicano por un selecto grupo de hombres prominentes novohispanos. El resultado de esta planeación fue un novedoso ensayo de repoblamiento español — real y privado — a partir de un proyecto colonizador racional y limitado, prohijado en el seno del gobierno central que en manos de los particulares prometía cumplir algunos de los objetivos y de las prácticas que ciertos funcionarios ilustrados perseguían a mediados del siglo XVIII en beneficio del imperio español. ${ }^{33}$

La propuesta fundamental para dar cauce al nuevo esquema colonizador y defensivo se centró en el establecimiento de nuevas poblaciones españolas, resguardadas principalmente por escuadras militares y compañías volantes, así como la pronta y cabal secularización de las misiones que pudieran subsistir con el pago de las obvenciones de los vecinos arraigados en la zona. La creación de poblados mixtos, en donde convivieran los indios y los vecinos fue otra de las propuestas que completan este nuevo afán colonizador. Ni duda cabe de que la presencia de los franciscanos era necesaria en tanto se echaba a andar y se consolidaba el nuevo proyecto. Asimismo estaba previsto que una vez que los tiempos políticos fueran favorables se habría de prescindir de manera definitiva de dicha institución. Por lo pronto, había que sacar provecho de su utilidad así fuera esta mediatizada. ${ }^{34}$

Ciertamente, la mirada puesta por el marqués en instaurar un nuevo orden político y social donde prevaleciera la población española sobre la indígena avizoraba la crisis en la que de manera indefectible tenderían a

33 Osante, 2005, 227-251.

34 Osante, 1997, 127-128. 
caer los distritos misionales, ante la consolidación del poblamiento hispano en la frontera norte de la Nueva España. Esta situación se iría reforzando cada vez más ante el hecho consumado de que en diversas regiones norteñas la misión, para su subsistencia, empezó a depender de las actividades realizadas fuera de los asentamientos misionales, tal y como sucediera con la fundación de la Colonia del Nuevo Santander. El noreste es entonces la región donde ya se percibe políticamente el declive de los centros misionales que desde el siglo XVI fueran autorizados por la Corona con la expectativa de facilitar «el control social, económico, político, fiscal y religioso de la población indígena que tenía patrones de asentamiento caracterizados por la dispersión territorial». ${ }^{35}$

Para el caso del Nuevo Santander, el auditor se inclina por una ocupación útil del territorio, junto con una mejor integración de la sociedad ahí asentada, tanto indígena como española y demás «gente de razón». Desde luego que para lograr una mayor afluencia de nuevos pobladores y preservar la población asentada en dicha región, Altamira propone aplicar programas de poblamiento que se puedan sufragar por sí mismos, a fin de controlar el desmedido gasto que provoca al real erario el sostenimiento de las nuevas fundaciones. ${ }^{36}$

En sus dictámenes, de manera reiterada, el marqués de Altamira expresa la necesidad de poblar lo conocido, pues señala que «no estando cubierto lo descubierto es irse descubriendo cuanto más se descubre adelante». Es decir, el auditor rechaza la expansión mientras las provincias norteñas no sean autosuficientes y continúen subsidiadas por el real gobierno. ${ }^{37} \mathrm{El}$ trabajo remunerado a los indígenas, afirma el auditor, no solo coadyuva a la sociabilidad y a la enseñanza de los naturales, sino que evita que estos vuelvan a la vida silvestre, aumentando con ello las posibilidades del tan esperado auge económico en el Nuevo Santander. ${ }^{38}$

Por otra parte, el interés del auditor por encontrar un hombre diligente, capaz de ejecutar la difícil empresa de pacificación y colonización del antiguo Seno Mexicano lo habrá de centrar en la figura del coronel José de Escandón y Helguera, quien a partir de su actividad desplegada en la Sierra

35 Para el estado de las misiones en el noroeste novohispano en la segunda mitad del siglo XVIII, véase Torre, 2009, 307-322.

36 Covarrubias, 2005, 280; AGI, Guadalajara, 191, 100v-101, Dictamen del marqués sobre los presidios de Nueva Vizcaya, 25 de febrero de 1751; AGI, México, 690, 9. a, 135-138v, Parecer del marqués Altamira sobre las misiones de Sierra Gorda.

37 AGI, Guadalajara, 191, 99v-106, Dictamen del marqués sobre presidios.

38 AGI, México, 690, 9. a, 135-138v, Parecer sobre las misiones de Sierra Gorda. 
Gorda se presenta con la capacidad probada en la procuración de un servicio de utilidad pública, esto es, el tipo de individuo al que los funcionarios reales deben permitir la participación en empresas públicas ventajosas para el imperio español. Además se trata de un personaje que promete no «alterar las dimensiones del territorio en que se asienta la población y mucho menos si esta se encuentra en proceso de disminución», tal y como lo ejecutara en la región queretana. En síntesis, Escandón se ajustaba cabalmente a la concepción que tanto Altamira como otros funcionarios reales habían defendido sobre cómo debían poblarse las tierras septentrionales. ${ }^{39}$

Pero es un hecho que no solo Altamira se encargó de ponderar los magníficos logros de la empresa ejecutada por Escandón. El virrey Revillagigedo - copartícipe de la política colonizadora delineada por Altamira para las provincias norteñas- en sus decretos, cédulas y demás correspondencia también suele emitir elogios desmedidos respecto de los resultados obtenidos por dicho coronel en el Seno Mexicano. Por ejemplo, no dudaban ambos funcionarios de que con el nuevo modelo colonizador ya puesto en marcha el real erario no solo obtendría un gran ahorro en la empresa, sino también se sacarían jugosos beneficios económicos una vez que se desarrollaran ampliamente, como se esperaba, las actividades económicas en toda la región del noreste. Entre estas últimas estaba el proyecto del puerto ubicado en la ría de Soto la Marina para comerciar, en principio, de manera directa con Veracruz, para posteriormente hacer el intercambio mercantil con el Caribe, Campeche, Venezuela, y de ser posible hasta con la misma España. ${ }^{40}$

Como se sabe, la empresa escandoniana, aunque respondió a las expectativas del gobierno real en el sentido de poblar con españoles y «gente de razón» la costa del Seno Mexicano para integrarla al resto de la Nueva España y defenderla de los indígenas rebeldes y de los extranjeros, esto no sucedió con los beneficios económicos que esperaban las autoridades virreinales, producto del comercio, de la explotación de la tierra y del uso de la mano de obra principalmente mestiza. En realidad, toda la utilidad de las transacciones mercantiles quedó en manos del gobernador de la provincia, el coronel José de Escandón, y de sus subalternos más inmediatos. Con

39 Covarrubias, 2005, 287.

40 AGI, México, 691, 12v-31v, Testimonio de los autos hechos a consulta del coronel Escandón, México, 27 de noviembre de 1751; AGNM, Provincias Internas, 173, exp. 1, 1-26; AGNM, Provincias Internas, 173, exp. 1, 68v-69, Decreto del virrey, primer conde de Revillagigedo, México, 17 de abril de 1752 . 
esto quiero decir que el proyecto colonizador formalmente se ejecutó conforme los lineamientos previstos por Altamira y otros altos funcionarios virreinales, pero una vez consolidada la colonización, el gobernador se encargó de mirar por sus propios intereses y los del grupo de hombres prominentes que lo apoyaban. Finalmente, lo sabemos, la nueva modalidad colonizadora terminó por servir a los intereses económicos y políticos de los principales inversionistas, quienes — además de aportar parte importante de los recursos, materiales y humanos para la fundación del Nuevo Santander - se encargaron de dirigir y controlar el destino de los habitantes de la nueva provincia. ${ }^{41}$

Así todo, los buenos resultados de la peculiar colonización del Seno Mexicano, motivaron a los funcionarios reales a hacerlo extensivo a otras provincias de la frontera norte. El noroeste sería ahora el elegido. Aun cuando desde algunos años antes de 1750 existía ya un particular interés por la provincia de Sonora y Sinaloa, no fue hasta los inicios de dicha década cuando el real gobierno habría de intentar aplicar algunos cambios importantes, luego de la destitución de Agustín Vildósola y la llegada de José Rafael Rodríguez Gallardo, en calidad de visitador y gobernador interino de dicha entidad. Este último funcionario, dados los buenos resultados que el coronel Escandón había logrado en el poblamiento del Seno Mexicano, propuso seguir el mismo criterio en cuanto a la reducción de indios y su integración en los pueblos de españoles como para el establecimiento de las villas de españoles en la provincia de Sonora y Sinaloa. ${ }^{42}$

Altamira, por su parte, en un prolífico dictamen sobre Sonora elaborado el 2 de octubre de 1747, hace patente su gran preocupación por el despoblamiento español de esa gobernación. ${ }^{43}$ Para el auditor el problema más serio era el deterioro social y económico que daba pie a las invasiones apaches, y no como se pensaba que eran precisamente estas la causa del deterioro de la provincia. En su profusa argumentación, el auditor hace ver que la raíz de todos los males en la región del noroeste es la frágil y malograda

41 Osante, 2003, 220-227.

42 Aun cuando Cinthia Radding menciona que Rodríguez Gallardo propone una nueva estructura para los pueblos de indios en Sonora, y Susan M. Deeds ve una similitud entre las propuestas de Rodríguez Gallardo y el marqués de Altamira, en cuanto a la secularización de las misiones y la importancia del trabajo indígena para la consolidación del poblamiento español, estas autoras no mencionan el particular señalamiento que hace el mencionado gobernador interino de Sonora en su Informe. Radding, 1997, 42-43. Deeds, 2003, 172-173. Rodríguez, 1975.

43 AGNM, Inquisición, 1282, exp. 10, 357-360, Dictamen del marqués de Altamira sobre Sonora, México, 2 de octubre de 1747. 
colonización española, a consecuencia de la política segregacionista aplicada por los religiosos, en este caso los jesuitas. ${ }^{44}$

A pesar de contar con el apoyo y la convicción reformista de Rodríguez Gallardo, las acciones transformadoras planeadas por Altamira para el noroeste, tuvieron que ser postergadas hasta la llegada del visitador José de Gálvez a la Nueva España en 1765. En efecto, el impulso reformista de finales de los años cuarenta y principios de los cincuenta se vio seriamente afectado por la fuerza política y económica que ostentaban los jesuitas, así como por la problemática situación que se vivía en Sonora y Sinaloa, debido a los abiertos enfrentamientos entre los grupos dominantes que se disputaban el poder político de la región que, lejos de favorecer a la causa del gobierno central, tendieron a complicarla aún más. ${ }^{45}$

Sería a mediados de la mencionada década de los sesenta cuando el visitador Gálvez implantaría personalmente la reforma tendiente a transformar al gobierno y a la sociedad arraigada en el noroeste de la Nueva España. Asimismo, en 1769 este mismo personaje habría de ensayar una nueva modalidad colonizadora en dicha región con la fundación de Alta California, ahora sí con un doble propósito: expansionista y defensivo. En ella retomaría el visitador la institución misión-presidio para la pacificación y la evangelización de los indígenas, pero bajo el mando de un gobierno militar. Asimismo, volvería a poner en práctica la estrategia del poblamiento masivo ensayado en la Colonia del Nuevo Santander, mediante el traslado de familias, principalmente de Sonora y Sinaloa, con una respuesta civil bastante limitada. ${ }^{46}$ Estas acciones emprendidas por Gálvez constatan la continuidad que en este importante periodo de la historia novohispana llamado comúnmente «reformas borbónicas», tuvieron algunas de las ideas y las propuestas que sobre la pacificación y la colonización de la frontera norte de México propusiera y estimulara desde la corte virreinal el marqués de Altamira durante más de una década. Refuerza esta última aseveración el hecho de que José de Gálvez, a lo largo de su trabajo reformador y colonizador efectuado en el noroeste novohispano, tuviera presente la copiosa información sobre las circunstancias históricas y la problemática norteña que el marqués de Altamira aportara en un cúmulo de dictámenes, informes y representaciones. De estos mismos documentos también se nutrirían el primer comandante de las Provincias Internas, Teodoro de Croix, así como el

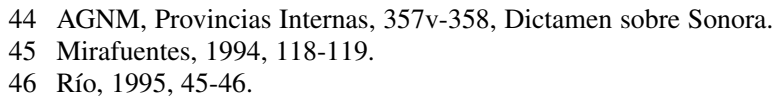


franciscano Juan Agustín Morfi durante el recorrido que ambos realizaran entre 1777 y 1781 por las provincias septentrionales, con un propósito similar al del marqués de Altamira centrado, recordemos, en la reorganización social, política y económica de los asentamientos norteños. ${ }^{47}$

Sin duda alguna, se habrá de reconocer que al empeñoso marqués de Altamira le hizo falta en sus dictámenes y pareceres la rica experiencia que habría significado una visita oficial por la compleja frontera norte, toda vez que, a la hora de intentar aplicar la incipiente reforma que pretendía, habría podido contar con mayores elementos de juicio, más allá de los intereses del grupo de nobles propietarios al que pertenecía. Sobre todo, dicho funcionario podría haber valorado en su real dimensión el importante y difícil papel que hubieron de desempeñar todos los habitantes del norte novohispano - civiles, militares, religiosos e indígenas- para sobrevivir en tan alejadas e ignotas tierras.

Recibido el 4 de septiembre de 2014 Aceptado el 20 de noviembre de 2014

\section{Bibliografía}

Alessio Robles, Vito: Coahuila y Texas en la época colonial, México, Porrúa, 1938.

Covarrubias, José Enrique: En busca del hombre útil. Un estudio comparativo del utilitarismo neomercantilista en México y Europa, 1748-1833, México, Universidad Nacional Autónoma de México, 2005.

Cramaussel, Chantal: «Un projet de réductions indigènes pour la NouvelleBiscaye. L'avis de Nicolás de Barreda, missionnaire jésuite à San Andrés en 1645», en Calvo, Thomas y Musset, Alain (dirs.), Des Indes Occidentales à l'Amérique Latine. Mélanges en hommage à Jean-Pierre Berthe, Paris, CEMCA/ENS/IHEAL, 1997, vol. 1, 39-55.

Cramaussel, Chantal: Poblar la frontera. La provincia de Santa Bárbara en Nueva Vizcaya durante los siglos XVI y XVII, México, El Colegio de Michoacán, 2006.

Deeds, Susan M.: Defiance and Deference in Mexico s Colonial North. Indias under Spanish Rule in Nueva Vizcaya, Austin, University of Texas Press, 2003.

47 Velázquez, 1979, 168. 
Mendizábal, Miguel Othón de: Compendio histórico de Zacatecas, en Obras completas, México, Talleres Gráficos de la Nación, 1946, tomo V.

Mirafuentes, José Luis: «Estructuras de poder político, fuerzas sociales y rebeliones indígenas en Sonora (siglo XVIII)», Estudios de Historia Novohispana, 14, México, 1994, 117-143.

Navarro García, Luis: Don José de Gálvez y la Comandancia General de las Provincias Internas del Norte de Nueva España, Sevilla, Escuela de Estudios Hispano-Americanos, CSIC, 1964.

Ortega Noriega, Sergio: «El sistema de misiones jesuíticas, 1591-1699», en Ortega, Sergio y Río, Ignacio del (coords.), Tres siglos de historia sonorense, 1530-1830, México, Universidad Nacional Autónoma de México, 2010, 41-95.

Ortega Noriega, Sergio y Río, Ignacio del (coords.): Tres siglos de historia sonorense, 1530-1830, 2. ${ }^{a}$ ed., México, Universidad Nacional Autónoma de México, 2010.

Ortega Soto, Martha: «La colonización en la primera mitad del siglo XVIII», en Ortega Noriega, Sergio y Río, Ignacio del (coords.), Tres siglos de historia sonorense, 1530-1830, México, Universidad Nacional Autónoma de México, 2010, 187-245.

Ortelli, Sara: «Guerra y pacificación en las fronteras hispanoamericanas coloniales. La provincia de Nueva Vizcaya en tiempos de los Borbones», en Bernabéu Albert, Salvador (coord.), El Gran Norte mexicano, indios, misioneros y pobladores entre el mito y la historia, Sevilla, Consejo Superior de Investigaciones Científicas, Escuela de Estudios Hispano-Americanos, 2009, 67-94.

Osante, Patricia: «Presencia misional en Nuevo Santander en la segunda mitad del siglo XVIII. Memoria de un infortunio», Estudios de Historia Novohispana, 17, México, 1997, 107-145.

Osante, Patricia: Orígenes del Nuevo Santander 1748-1772, México, Universidad Nacional Autónoma de México/Universidad Autónoma de Tamaulipas, 2003.

Osante, Patricia: «Colonization and Control: The Case of Nuevo Santander», en Teja, Jesús F. de la y Frank, Ross (eds.), Choice, Persuasion and Coercion: Social Control on Spain's North American Frontiers, Albuquerque, University of New Mexico Press, 2005, 227-251.

Osante, Patricia: «Del Cantábrico al Seno Mexicano: José de Escandón en Nueva España», en Bernabéu Albert, Salvador (coord.), El Gran Norte mexicano. Indios, misioneros y pobladores entre el mito y la historia, Sevilla, CSIC, EEHA, 2009, 331-361.

Osante, Patricia: Poblar el septentrión. I. Las ideas y las propuestas del marqués de Altamira 1742-1753, México, Universidad Nacional Autónoma de México, 2012. 
Polzer, Charles W. y Sheridan, Thomas E. (eds.): The Presidio and Militia on the Northern Frontier of New Spain, Tucson, University of Arizona Press, 1997, 2 vols.

Porras Muñoz, Guillermo: La frontera con los indios de Nueva Vizcaya en el siglo XVII, México, Fomento Cultural Banamex, 1980.

Radding, Cynthia: Wandering Peoples. Colonialism, Ethnic Sapaces, and Ecological Frontiers in Northwestern Mexico, 1700-1850, Durham and London, Duke University Press, 1997.

Río, Ignacio del: La aplicación regional de las reformas borbónicas en Nueva España. Sonora y Sinaloa, 1768-1787, México, Universidad Nacional Autónoma de México, 1995.

Rivera, Pedro de: Diario y derrotero de lo caminado, visto y observado en la visita que hizo a los presidios de la Nueva España septentrional el brigadier Pedro de Rivera, introducción y notas de Vito Alessio Robles, México, Secretaría de la Defensa Nacional, Dirección del Archivo Militar, 1946.

Rodríguez Gallardo, Rafael: Informe sobre Sinaloa y Sonora, año de 1750, edición, introducción y notas, German Viveros, México, Archivo General de la Nación, 1975.

Serrera Contreras, Ramón María: Guadalajara ganadera. Estudio regional novohispano, 1760-1805, Sevilla, Escuela de Estudios Hispano-Americanos, CSIC, 1977.

Torre Curiel, José Refugio de la: «La frontera misional novohispana a fines del siglo XVIII: un caso para reflexionar sobre el concepto de misión», en Bernabéu Albert, Salvador (coord.), El Gran Norte mexicano. Indios, misioneros y pobladores entre el mito y la historia, Sevilla, CSIC, EEHA, 2009, 285-330.

Velázquez, María del Carmen: Establecimiento y pérdida del septentrión de Nueva España, México, El Colegio de México, 1974.

Velázquez, María del Carmen: El marqués de Altamira y las provincias internas de Nueva España, México, El Colegio de México, 1979.

Velázquez, María del Carmen: «Don Matías de la Mota y Padilla y su política de poblamiento», Estudios de Historia Novohispana, 7, México, 1981, 79-98.

Weber, David J.: The Spanish Frontier in North America, New Haven, Conn., Yale University Press, 1992. 